\title{
Tinea capitis: STUDY OF ASYMPTOMATIC CARRIERS AND SICK ADOLESCENTS, ADULTS AND ELDERLY WHO LIVE WITH CHILDREN WITH THE DISEASE
}

\author{
Christiane Loureiro BERGSON(1) \& Nurimar Conceição FERNANDES(2)
}

\begin{abstract}
SUMMARY
Tinea capitis is a dermatophyte infection that occurs mainly in childhood; there are few reports, in Brazil, in adolescents and adults. The detection of asymptomatic carriers is of great importance in the disease control. From February 1998 to February 1999 , a study was performed at the outpatient Dermatologic Unit of Instituto de Puericultura e Pediatria Martagão Gesteira (Universidade Federal do Rio de Janeiro, Brasil) to verify the frequency of asymptomatic carriers and tinea capitis between 79 adolescents, adults and elderly who lived in the same household of 56 children (0-12 years) with tinea capitis. Of these, one female and one male adults $(2.5 \%)$ were asymptomatic carriers and the cultures revealed Trichophyton tonsurans and Microsporum canis respectively. One female adolescent and two female adults (3.8\%) had tinea capitis and all cultures revealed Trichophyton tonsurans. The study has shown that adolescents and adults who live in the same household of children with tinea capitis may be sick or asymptomatic carriers.
\end{abstract}

KEYWORDS: Tinea capitis; Carrier; Adolescence; Adult; Elderly

\section{INTRODUCTION}

Dermatophytoses are cutaneous mycoses, endemic in Latin America and a worldwide public health problem. Tinea capitis is a dermatophyte infection of the scalp with a wide range of clinical presentations: hair loss with or without broken hairs; diffuse or focal scaling of varying severity, with or without erythema and lesions resembling impetigo, folliculitis decalvans or scalp cellulitis ${ }^{7}$. It is a sanitary problem of great importance in Brazil because it is the commonest cutaneous fungal infection in children. The main isolated dermatophytes are Microsporum canis and Trichophyton tonsurans ${ }^{48}$.

Tinea capitis is also reported worldwide in adolescents, adults and elderly in variable percentages; from 1949 to 1998, the following figures are reported:

- 55 cases in adolescents ( 37 female and 18 male), with isolation of $T$. tonsurans (15 cases), T. violaceum (5 cases), T. mentagrophytes (4 cases), T. verrucosum ( 3 cases), M. canis ( 2 cases), T. soudanense (1 case) and M. ferrugineum ( 1 case $)^{1,9,16,21,24,25,28,36,52}$.

- 90 cases in adults (79 female and 11 male), with isolation of $T$. tonsurans (32 cases), T. violaceum (27 cases), M. canis (18 cases), T. mentagrophytes (3 cases), M. langeronii (3 cases), T. rubrum ( 2 cases), T. soudanense (2 cases), M. audouinii (1 case), T. verrucosum ( 1 case) and $M$. ferrugineum (1 case) $)^{2,6,7,8,10,12,16,18,22,24,28,32,36,46,50,53,55,56}$.
- 27 cases in female elderly, with isolation of M. canis (13 cases), T. tonsurans (6 cases), T. violaceum (4 cases), T. rubrum ( 3 cases) and M. gypseum (1 case) $)^{6,11,12,16,17,18,20,24,28,32,33,36,39,41,49,50,55}$.

In Brazil, from 1959 to 1995, one case was reported in adolescent (sex not related), with isolation of T. tonsurans ${ }^{35}$ and four cases in female adults, with isolation of T. tonsurans ( 2 cases) and M. canis (2 cases $)^{31,34,40,43}$.

T. tonsurans can cause infection with no evidence of clinical disease $^{5}$, what makes its control difficult. A healthy adult carrier can reinfect the children ${ }^{5}$ and has epidemiological implications because silent focuses of infection are more difficult to detect and eradicate ${ }^{19}$.

The following criteria define the asymptomatic carrier state: 1) no clinical signs of tinea capitis: alopecia, scaling, erythema, broken hairs, black dots, crusts, inflammatory lesions, favus and pruritus ${ }^{5,19,44}$; and, 2) infected hairs, with isolation of the dermatophyte t, $^{5,30,37,42,44,45,51}$.

The asymptomatic carriers among children and adolescents are observed in percentages varying from $0.2-37.2 \%$, occurring mainly in female, with predilection of anthropophilic dermatophytes; in adults, in percentages varying from $11.4-30.4 \%$, with predilection also in female and isolation of only anthropophilic fungi (T. tonsurans and $T$. violaceum). 
Considering the few reports in Brazil and worldwide, we proceeded an investigation about this subject to verify: 1) the frequency of asymptomatic carriers in adolescents, adults and elderly who live in the same household of children with tinea capitis; and, 2) the frequency of tinea capitis in adolescents, adults and elderly who live in the same household of children with this fungal infection.

\section{PATIENTS AND METHODS}

1 - Patients: From February 1998 to February 1999, a study was performed at the outpatient dermatologic unit of IPPMG (UFRJ), with 56 children ( 0 - 12 years) with tinea capitis and 6 adolescents $(13-18$ years), 71 adults (19-64 years) and 2 elderly (65 years or more) who lived in the same household of these children. The scalps were examined for clinical signs of infection, such as scaling, black dots, broken hairs, alopecia, lymphadenomegaly, erythema, edema, kerion, folliculitis and atrophy.

\section{2 - Methods:}

2.1 - The specimens (pus, scales and 12 or more hairs) obtained from the lesions were submitted to mycological examination in the Mycology Laboratory - HUCFF - UFRJ. The number of 12 hairs was fixed to obtain an enough large sample.

In the adolescents, adults and elderly with lesions, specimens were collected from the most representative area beyond 12 or more separate hairs from biparieto-occipital area; in people without lesions, 12 or more separate hairs from biparieto-occipital area were collected to settle the method.

2.2 - Processing of specimens: Clarification with $\mathrm{KOH} 20 \%+$ DMSO for direct microscopy and culture in Sabouraud Dextrose-Agar (Difco) and Mycobiotic Agar (Difco).

\section{RESULTS}

Among the 56 children with tinea capitis, 25 male and 12 female were up to 5 year-old; 10 male and 9 female were 6 to 12 year-old. Children up to 5 year-old accounted for $66.0 \%$ of the sample and males, $62.5 \%$.

The direct microscopy examination was positive in $89.2 \%$ of the 56 cases of tinea capitis in children and the culture in $98.2 \%$. The following dermatophytes were isolated: M. canis (35/62.5\%), T. tonsurans (15/ $26.8 \%)$, T. mentagrophytes (4/7.1\%) and T. rubrum (1/1.8\%).

Among the 79 adolescents, adults and elderly living with the children, one female and one male adults $(2.5 \%)$ were asymptomatic carriers, while three female patients (one adolescent and two adults) (3.8\%) had tinea capitis.

The diagnosis of the two asymptomatic carriers, established by culture, revealed T. tonsurans and M. canis in each case. Among the contacts with tinea capitis, the culture was positive in all the cases $(T$. tonsurans), while only one case had positive direct microscopy examination (endothrix infection).

\section{DISCUSSION}

Our sample of tinea capitis in children was characterized by higher frequency between $0-5$ years $(66.0 \%)$ and in males $(62.5 \%)$. However, in the literature, there are reports with preponderance in the ages $0-5^{26,29}$, $1-5^{52}, 5-10^{23}, 6-12^{9,45,47}$ and $7-12^{15}$ and male predominance ${ }^{15,23,26,47,54}$. These findings can be explained by several variables: short hairs making easier the implantation of spores ${ }^{23}$, dressing with petrolatum or other oils acting as an adherent for the arthroconidium ${ }^{44}$ and cosmetic oils inhibiting the dermatophyte colonization ${ }^{3}$.

In our study, the direct microscopy was positive in $89.2 \%$ of the cases, while the culture in $98.2 \%$. M. canis was the most prevalent fungus $(62.5 \%)$, followed by $T$. tonsurans $(26.8 \%)$, T. mentagrophytes $(7.1 \%)$ and T. rubrum (1.8\%). Our findings are in agreement with papers observing higher frequency of $M$. canis in Southeast and South (Brazil) $)^{13,27,38}$ and T. tonsurans in North and Northeast (Brazil) ${ }^{15,45,54}$, as well as with greater percentage of positivity in the culture ${ }^{45}$.

The finding of two asymptomatic carriers $(2.5 \%)$ makes possible to affirm, with $95 \%$ of confidence, that the true proportion of asymptomatic carriers in adolescents, adults and elderly who live with the infected children varies from $0.3-8.8 \%$. These cases were diagnosed only by culture (T. tonsurans and M. canis).

In a study with 26 adults who are asymptomatic contacts of children with tinea capitis $^{7}$, five female asymptomatic carriers of $T$. violaceum (19.2\%) were diagnosed by culture. The methodology used for hair collection and the studied period were not mentioned.

In a study with 46 asymptomatic adults who lived with 50 children with tinea capitis caused by $T$. tonsurans ${ }^{5}, 14$ asymptomatic carriers of this fungus $(30.4 \%)$ were diagnosed by the culture, 13 female $(92.9 \%)$. The methodology used for hair collection and the studied period were also not mentioned by the authors.

Four asymptomatic carriers $(11.4 \%)$ of $T$. tonsurans were found between 35 adults who lived with children with tinea capitis $^{51}$. It was used the toothbrush scrapings technique.

In another study ${ }^{45}, 16$ adults $(13.1 \%)$ who lived with children with tinea capitis by $T$. tonsurans were asymptomatic carriers ( 14 female and 2 male) diagnosed by culture of material collected from bi-parieto-occipital area.

The percentage of asymptomatic adults carriers in our study (2.5\%) is smaller because T. tonsurans, anthropophilic fungus, is less prevalent in Rio de Janeiro and endemic in Amazonas. The differences in host susceptibility and species virulence are also determinant factors ${ }^{19}$.

Considerating the prevalence of $T$. violaceum in South Africa ${ }^{7}$ and T. tonsurans in USA ${ }^{5,51}$ and Amazon ${ }^{45}$, it would be expected a higher percentage in these areas, since anthropophilic fungi infection spreads easily in human beings.

Only one study ${ }^{45}$ employed a similar methodology to ours; however, there were three differences: a smaller number of collected hairs 
(at least 6 in the biparieto-occipital area), the inclusion of only asymptomatic carriers of $T$. tonsurans and in the studied period (20 months).

We found one asymptomatic female carrier of $M$. canis who lived with a child with tinea capitis caused by the same fungus. This patient had a dog and a cat in her household which were the probable focuses. Although rare, it is possible to speculate about the hypothesis of human transmission $^{37}$ (child-adult or adult-child).

M. canis can be transmitted from human to human, but it may lose its virulence after about four human to human transmissions; thus, it is necessary an animal host to regain the virulence ${ }^{4}$. Zoophilic fungi cause a brisk inflammatory response in nearly all infected people and are less likely to cause an asymptomatic carrier state ${ }^{14}$.

M. canis was isolated from the healthy children and adolescents" scalps in variable percentages $(0.2-12.7 \%)^{30,37,42}$. The culture samples were obtained with a hairbrush or sterilized carpet discs over the entire surface of the scalp.

The greater percentage $(12.7 \%)^{30}$ occurred in classes with clinical cases of tinea capitis. This fact suggests the possibility of human to human transmission, although there is no reference about contact with domestic animals.

POLONELLI et al $^{37}$ found one asymptomatic carrier of M.canis (who did not have history of contact with domestic animals) between 754 healthy students.

ROSS et al. ${ }^{42}$ also found one asymptomatic carrier of this fungus between 95 healthy children, but he did not relate if there was history of contact with domestic animals.

The reports of asymptomatic carriers of $M$. canis between children and adolescents could be explained by the close contact with cats and dogs; on the other hand, there were no adult cases.

The two asymptomatic carriers of our study were diagnosed only by the culture; this method is essential for the definition of asymptomatic carrier state ${ }^{45}$.

We found three $(3.8 \%)$ female people with tinea capitis (one adolescent and two adults) by $T$. tonsurans. We can affirm, with $95 \%$ of confidence, that the true proportion of tinea capitis in these people who lived with the index cases ranges from 1.0-11.4\%.

In a period of 49 years, there were 55 world reported cases of tinea capitis affecting adolescents (37 female $(68.4 \%)$ ) and 90 adults (79 female $(87.7 \%)$ ). In Brazilian literature, in a period of 36 years, there were reported one adolescent case (sex not related) and four female adults. However, it is impossible to know the true casuistic of published Brazilian and foreign cases because the ages are not defined according to OMS. Our finding of higher frequency between female adolescents and adults is in accordance with Brazilian and worldwide literature.

The adolescent patient had only one sign of disease - scaling on the vertex. In worldwide literature, there was mainly inflammatory tinea capitis, although several clinical aspects and etiological agents could be found. The Brazilian case in the adolescence had no clinical description, but was caused by $T$. tonsurans, as in our related case.

The two adult patients presented diffuse scaling of the scalp. In worldwide literature, there is a great diversity of clinical aspects and etiological agents. In Brazil, the adults mainly presented alopecic plaque, with broken hairs and scaling. M. canis and T. tonsurans were isolated in these cases.

In our study, positive direct microscopy (33.3\%) and culture (100.0\%) were observed in the three contact cases with tinea capitis. Literature data about tinea capitis in adolescents, adults and elderly in general give variable percentage of positivity of direct microscopy: $100.0 \%^{2,20,22,32,34,36,39,43,49,55}, 66.7 \%^{7}$ and $33.3 \%^{53}$. Regarding the culture, the fungus was also isolated in variable proportions: adults and elderly $(100.0 \%)^{2,7,12,16,18,24,28,36,53,55}$ and adolescents $\left(26.0 \%{ }^{1}\right.$ and $100.0 \%$ 9,16,21,24,25,35,36).

\section{CONCLUSIONS}

- Among the 79 adolescents, adults and elderly living with children with tinea capitis $2.5 \%$ ( 2 cases) were asymptomatic carriers (confidence interval $95 \%$ [0.3-8.8\%] ) and 3.8\% (3 cases) had the disease (confidence interval 95\% [1.0-11.4\%] ).

\section{RESUMO}

\section{Tinea capitis: estudo de portadores assintomáticos e doentes adolescentes, adultos e idosos coabitantes com crianças com a infecção}

A tinea capitis é uma infecção dermatofítica freqüente na criança; há relatos isolados, no Brasil, em adolescentes e adultos. A detecção do estado de portador assintomático tem importância primordial no controle desta infecção. No período de fevereiro de 1998 a fevereiro de 1999, no Ambulatório de Dermatologia do IPPMG (UFRJ), foi investigada a frequiência de portadores assintomáticos e doentes entre 79 coabitantes (adolescentes, adultos e idosos) com 56 crianças (0-12 anos) apresentando tinea capitis. Dos 79 coabitantes, uma mulher e um homem adultos $(2,5 \%)$ eram portadores assintomáticos, sendo isolados Trichophyton tonsurans e Microsporum canis respectivamente. Uma adolescente e duas adultas $(3,8 \%)$ apresentaram tinea capitis com isolamento de Trichophyton tonsurans. $\mathrm{O}$ estudo demonstrou que adolescentes e adultos coabitantes domiciliares com crianças com tinea capitis podem ser doentes ou portadores assintomáticos.

\section{ACKNOWLEDGEMENTS}

We are grateful to the Dermatology's Postgraduation Course (HUCFF-UFRJ), that gave us conditions to perform this work and to the Mycology Laboratory (HUCFF-UFRJ), that helped us in the processing of specimens collected.

\section{REFERENCES}

1. ALI-SHTAYEH, M.S. \& ARDA, H.M. - A study of tinea capitis in Jordan (West Bank). J. trop. Med. Hyg., 89: 137-141, 1986. 
2. ALTERAS, I. \& FEUERMAN, E.J. - Atypical cases of Microsporum canis infection in the adult. Mycopathologia (Den Haag), 74: 181-185, 1981.

3. ALY, R. - Ecology and epidemiology of dermatophyte infections. J. Amer. Acad. Derm., 31: S21-S25, 1994.

4. ALY, R. - Ecology, epidemiology and diagnosis of tinea capitis. Pediat. infect. Dis. J., 18: $180-185,1999$.

5. BABEL, D.E. \& BAUGHMAN, S.A. - Evaluation of the adult carrier state in juvenile tinea capitis caused by Trichophyton tonsurans. J. Amer. Acad. Derm., 21: 1209-1212, 1989.

6. BARGMAN, H.; KANE, J.; BAXTER, M.L. \& SUMMERBELL, R.C. - Tinea capitis due to Trichophyton rubrum in adult women. Mycoses, 38: 231-234, 1995.

7. BARLOW, D. \& SAXE, N. - Tinea capitis in adults. Int. J. Derm., 27: 388-390, 1988.

8. BOURNERIAS, I.; DE CHAUVIN, M.F.; DATRY, A. et al. - Unusual Microsporum canis infections in adult HIV patients. J. Amer. Acad. Derm., 35: 808-810, 1996.

9. BRONSON, D.M.; DESAI, D.R.; BARSKY, S. \& FOLEY, S.M.M. - An epidemic of infection with Trichophyton tonsurans revealed in a 20-year survey of fungal infections in Chicago. J. Amer. Acad. Derm., 8: 322-330, 1983.

10. CHEN, AW.J.; KUO, J.W.L.; CHEN, J.S.; SUN, C.C. \& HUANG, S.F. - Dermatophyte pseudomycetoma: a case report. Brit. J. Derm., 129: 729-732, 1993.

11. CONERLY, S.L. \& GREER, D.L. - Tinea capitis in adults over fifty years of age. Cutis, 41: 251-252, 1988.

12. CREMER, G.; BOURNERIAS, I.; VANDEMELEUBROUCKE, E.; HOUIN, R. \& REVUZ, J. - Tinea capitis in adults: misdiagnosis or reappearance? Dermatology, 194: 8-11, 1997.

13. FERNANDES, N.C.; MONTEIRO, P.C.F. \& PEREZ, M.A. - Dermatophytosis in children: risk factors study. J. Mycol. méd., 5: 188-189, 1995.

14. FRIEDEN, I.J. - Tinea capitis: asymptomatic carriage of infection. Pediat. infect. Dis. J., 18: 186-190, 1999.

15. FURTADO, M.S.S.; IHÁRA, L.T. \& MARÓJA, M.F. - Tinea capitis na cidade de Manaus, AM. An. bras. Derm., 60: 315-318, 1985.

16. GARCIA PEREZ, A. \& MORENO GIMENEZ, J.C. - Tinea capitis en adultos y adolescentes. Nota sobre ocho casos. Med. cut. ibero lat.-amer., 9: 329-336, 1981.

17. GAUVAIN, E.A. - Tinea capitis in an adult (Microsporum lanosum). Arch. Derm. Syph., 60: $860,1949$.

18. GIANNI, C.; BETTI, R.; PEROTTA, E. \& CROSTI, C. - Tinea capitis in adults. Mycoses, 38: 329-331, 1995.

19. GOSLEN, J.B. \& KOBAYASHI, G.S. - Fungal diseases with cutaneous involvement. Mycologic infections. In: FITZPATRICK, T.B.; EISEN, A.Z.; WOLFF, K. et al. Dermatology in general Medicine. 3. ed. New York, Mc Graw Hill, 1987. p. $2193-$ 2248.

20. GRIGORIU, D. \& CHESEAUX, A. - Infection microsporique du cuir chevelu chez un adulte. Dermatologica, 162: 313-317, 1981.

21. HOUCK, H.E.; COOLEY, J.E.; LOWITT, M.H. \& KAO, G.F. - Tinea caput medusa: an unusual presentation of Trichophyton mentagrophytes on the scalp. Cutis, 58: 48$52,1996$.

22. KAMALAM, A. \& THAMBIAH, A.S. - Lupus erythematosus like Tinea capitis caused by Trichophyton tonsurans. Mykosen, 27: 316-318, 1984.

23. KANWAR, A.J. \& BELHAJ, M.S. - Tinea capitis in Benghazi, Libya. Int. J. Derm., 26: 371-373, 1987.
24. LEE, J.Y.Y. \& HSU, M.L. - Tinea capitis in adults in Southern Taiwan. Int. J. Derm. 30: $572-575,1991$

25. LESTRINGANT, G.G.; QAYED, K. \& BLAYNEY, B. - Tinea capitis in the United Arab Emirates. Int. J. Derm., 30: 127-129, 1991.

26. LONDERO, A.T. - Microsporum infection in Rio Grande do Sul (Brazil). Derm. trop., 2: 164-167, 1963.

27. LONDERO, A.T. \& RAMOS, C.D. - Agentes de dermatofitoses humanas no interior do Estado do Rio Grande do Sul no período 1960-1987. An. bras. Derm., 64: 161-164, 1989.

28. MALEVILlE, J.; MOUliNiER, C.; TAÏEB, A. et al. - Évolution du spectre dermatophytique des teignes du cuir chevelu. Ann. Derm. Vénér., 113: 25-29, 1986.

29. McALEER, R. - Fungal infections of the scalp in Western Australia. Sabouradia, 18: 185-190, 1980.

30. MIDGLEY, G. \& CLAYTON, Y.M. - Distribution of dermatophytes and Candida spores in the environment. Brit. J. Derm., 86: 69-77, 1972.

31. MIRANDA, M.J.S.; SOARES, M.L.A.; TRAVASSOS, S.N. et al. - Tinea capitis em adulto. An. bras. Derm., 64: 137-140, 1989.

32. MOBERG, S. - Tinea capitis in the elderly. A report on two cases caused by Trichophyton tonsurans. Dermatologica, 169: 36-40, 1984

33. OFFIDANI, A.; SIMONCINI, C.; ARZENI, D. et al. - Tinea capitis due to Microsporum gypseum in an adult. Mycoses, 41: 239-241, 1998.

34. PADILHA GONÇALVES, A. \& LAMY, N. - Tinha tonsurante microspórica do couro cabeludo em adulto. An. bras. Derm. Sif., 34: 23-25, 1959.

35. PECHER, S. A.; CASTRO, G.B. \& BORRÁS, M.R.L. - Prevalência de micoses superficiais em escolares de localidades da região amazônica ocidental (fronteira Brasil-Colômbia). An. bras. Derm., 57: 13-18, 1982.

36. PIPKIN, J.L. - Tinea capitis in the adult and adolescent. Arch. Derm. Syph. (Chic.), 66: 9-40, 1952.

37. POLONELLI, L.; GARCOVICH, A. \& MORACE, G. - Dermatophyte carriers among school children. Mykosen, 25: 254-257, 1982.

38. PROENÇA, N.G. \& ASSUMPÇÃO, S.B.P. - Dermatofitoses nas crianças. Estudo de 139 casos. An. bras. Derm., 64: 113-114, 1989.

39. PURSLEY, T.V. \& RAIMER, S.S. - Tinea capitis in the elderly. Int. J. Derm., 19: 220, 1980.

40. RAMOS-E-SILVA, M.; TROPE, B.M.; CAIUBY, M.J. et al. - Tinea capitis in adult after local corticotherapy. Folha méd., 110: 73-76, 1995.

41. RIDLEY, C.M. - Tinea capitis in an elderly woman. Clin. exp. Derm., 4: 247-248, 1979.

42. ROSS, S.; RUBIANES, E.I.; LUGO-SOMOLINOS, A.; VAZQUEZ-BOTET, M. \& SANCHEZ, J.L. - Epidemiological study of tinea capitis in Puerto Rico. Puerto Rico Hlth. Sci. J., 12: 287-289, 1993.

43. SEVERO, L.C. \& GUTIERREZ, M.J. - Tinha do couro cabeludo por Microsporum canis em adulto. An. bras. Derm., 60: 87-88, 1985.

44. SHARMA, V.; HALL, J.C.; KNAPP, J.F. et al. - Scalp colonization by Trichophyton tonsurans in an urban pediatric clinic? A symptomatic carrier state. Arch. Derm., 124: $1511-1513,1988$

45. SOUSA, F.H.C. - Tinea capitis por Trichophyton tonsurans em crianças: papel dos portadores assintomáticos. Rio de Janeiro, 1997. (Dissertação de Mestrado Faculdade de Medicina da Universidade Federal do Rio de Janeiro). 
46. STEHLICH, G.; GILDE, K. \& TÖRÖK, I. - Tinea capitis caused by Microsporum canis in an adult. Mycoses, 32: 97-98, 1989.

47. TOWERSEY, L. - Contribuição ao estudo clínico-laboratorial e à epidemiologia da dermatofitose e afecções símiles. Rio de Janeiro, 1997. (Dissertação de Mestrado Faculdade de Medicina da Universidade Federal Fluminense).

48. TOWERSEY, L.; HAY, R.J.; MONTEIRO, M.H. et al. - Outbreak of tinea capitis by Trichophyton tonsurans and Microsporum canis in Niterói, RJ, Brazil. Rev. Inst. Med. trop. S. Paulo., 34: 233-238, 1992.

49. VAN HECKE, E. \& MEYSMAN, L. - Tinea capitis in an adult (Microsporum canis). Mykosen, 23: 607-608, 1980

50. VANNINI, P.; GUADAGNI, R.; PALLESCHI, G.M.; DIFONZO, E.M. \& PANCONESI, E. - Tinea capitis in the adult: two case studies. Mycopathologia (Den Haag), 96: 53-57, 1986

51. VARGO, K. \& COHEN, B.A. - Prevalence of undetected tinea capitis in household members of children with disease. Pediatrics, 92: 155-157, 1993.
52. VENUGOPAL, P.V. \& VENUGOPAL, T.V. - Tinea capitis in Saudi Arabia. Int. J. Derm 32: $39-40,1993$

53. VIDIMOS, A.T.; CAMISA, C. \& TOMECKI, K.J. - Tinea capitis in three adults. Int. J. Derm., 30: 206-208, 1991.

54. VIEIRA, J.R. - Considerações sobre a incidência de Tinea capitis no Recife. Hospital (Rio de J.), 67: 217-222, 1965.

55. VIGNALE, R.A.; PEREIRA, P.; CIVILA, E.; ARROYO, L. \& WITKIND, J. - Tiña microspórica de cuero cabelludo en adultos. Med. cut. ibero. lat.-amer., 11: 183186, 1983.

56 . YOUNG, M.; KEANE, C. \& ENGLISH, L. - Misdiagnosed dermatophytosis. J. Infect. 4: $127-129,1982$

Received: 08 June 2000

Accepted: 27 November 2000 